\title{
Enhancing the HVRT and LVRT Capabilities of DFIG-based Wind Turbine in an Islanded Microgrid
}

\author{
Arman Safaei \\ Electrical Engineering Department \\ Amirkabir University of Technology \\ Tehran, Iran \\ a.safaei@aut.ac.ir
}

\author{
Seyed Hossein Hosseinian \\ Electrical Engineering Department \\ Amirkabir University of Technology \\ Tehran, Iran \\ hosseinian@aut.ac.ir
}

\author{
Hossein Askarian Abyaneh \\ Electrical Engineering Department \\ Amirkabir University of Technology \\ Tehran, Iran \\ askarian@aut.ac.ir
}

\begin{abstract}
Doubly fed induction generator (DFIG) based wind turbines are very sensitive to grid voltage variations. Therefore, low-voltage-ride-through (LVRT) and high-voltage-ride-through (HVRT) capabilities are employed to improve DFIG performance during grid faults and voltage swell events. In this paper, a superconducting magnetic energy storage (SMES) device with a PWM voltage source converter and a DC-DC chopper is proposed to enhance the DFIG LVRT and HVRT capabilities in an islanded microgrid simultaneously. The simulation results demonstrate that the SMES absorbs or releases energy from/to the microgrid during voltage swell events and fault condition respectively and consequently, improves the DFIG performance and enhances the DFIG LVRT and HVRT capabilities. The effectiveness of the proposed method is validated through detailed simulations in PSCAD/EMTDC.
\end{abstract}

Keywords-doubly fed induction generator; microgrid; low voltage ride through (LVRT); high voltage ride through (HVRT); superconducting magnetic energy storage (SMES)

\section{INTRODUCTION}

The growth of renewable energy resources usage in the form of distributed generation is led to the introduction of the idea of microgrid. Microgrids have significant advantages such as reducing environmental effects, increasing energy efficiency, increasing reliability of supply and reducing power losses. They can operate in both grid-connected and islanded operation modes and they usually include different distributed generation sources (DGs) such as wind and solar generation, energy storages and loads [1]. Wind energy had a strong growth in the last decade among various renewable energy sources. In 2016, a capacity larger than $54.6 \mathrm{GW}$ of new wind power has been installed and the world's total installed wind capacity reached $486.8 \mathrm{GW}$ at the end of 2016. Global installed wind capacity is expected to reach $817 \mathrm{GW}$ at the end of 2021 [2]. Variable speed wind turbines with doubly fed induction generators (DFIGs) are generally used to generate electrical power in microgrids. DFIGs offer certain advantages such as, low converter capacity, high efficiency and ease controllability as they can operate under variable speed near their optimal turbine efficiency over a wide range of wind speed [3]. On the other hand, DFIGs are very sensitive to grid voltage variations. The voltage dip caused by grid faults at the connection point leads to increase the rotor current which may damage the rotor side converter and DC link capacitor if no protection scheme has been implemented. Also, voltage swell caused by unbalanced faults, large loads switching off and large capacitor banks energizing induce a big electromotive force (EMF) and a surge current in the DFIG rotor which will endanger the normal operation of the DFIG $[4,5]$. Disconnecting the DFIG from the grid during fault condition is the first solution that is used to protect the DFIG. However, with large integration of wind generators in the power system, loss of significant part of wind generators following a fault may endanger the whole system's stability. Therefore, to ensure the reliable operation of the grid, DFIG-based WTs must tolerate grid turbulences and support the network. So, low voltage ride through (LVRT) and high voltage ride through (HVRT) schemes are implemented.

Different LVRT methods have been used to meet grid code requirements. Usually to provide complete LVRT capability, additional circuits are required. The primary scheme to protect DFIG converters from over current during fault conditions is short circuiting the DFIG rotor windings by a system called crowbar [6]. However, with crowbar operation, the rotor side converter is deactivated and the DFIG control is lost. The effectiveness of installing fault current limiters (FCLs) on the LVRT capability of the DFIG has been evaluated in $[7,8]$. A modified flux-coupling-type superconducting fault current limiter (SFCL) is applied to improve the LVRT capability of DFIG in [7] and the bridge-type fault current limiter (BTFCL) impacts on the LVRT capability of DFIG has been investigated in [8]. The effectiveness of FACTS devices such as dynamic voltage restorer (DVR), STATCOM and SVC on the LVRT capability of the DFIG has been studied in [9, 10]. Dynamic voltage restorer (DVR) has been proposed to improve LVRT capability of the DFIG in [9] and the STATCOM has been used to enhance DFIG LVRT capability in [10]. However, these methods require more hardware which leads to a decrease in reliability and an increase in hardware costs. Different SMES configurations have been employed to enhance transient stability of the DFIG $[11,12]$. Series and parallel compensation using SMES has been used to improve power and voltage variations of the wind turbine in [11]. The coordinated control of the optimized resistive type superconducting fault current limiter (SFCL) and SMES has been applied for transient stability enhancement in [12]. 
However, as the SMES has no effect on the alleviation of DFIG terminal voltage drop during fault condition, the LVRT capability cannot be guaranteed. Various control strategies including virtual damping flux-based control, scaled current tracking control, and sliding mode control have been proposed to enhance DFIG LVRT capability in [13-15]. However, these control schemes increase the complexity of the DFIG control and the difficulty of coordination between normal and faulty conditions. Recent researches only focus on the effects of grid voltage dip on the DFIG while the effect of grid voltage swell has received less consideration. Also, previous studies have mainly focused on improving the DFIG LVRT capability in normal networks (not microgrids). Therefore, the DFIG LVRT capability during fault condition in an islanded microgrid is investigated in detail in this study. In this paper, important effort has been devoted to evaluate the effectiveness of applying the SMES unit with a PWM voltage source converter and a DC-DC chopper on the DFIG LVRT and HVRT capabilities in an islanded microgrid during faults and voltage swells.

\section{SYSTEM MODELLING}

\section{A. DFIG Modeling}

The DFIG consists of a back-to-back voltage-source converter including a rotor side converter (RSC) and a grid side converter (GSC). As shown in Figure 1, the stator is directly connected to the constant frequency three-phase grid and the rotor winding is connected to a back-to-back converter. The RSC is used to regulate torque and reactive power injection of the DFIG. Also, the GSC is used to control the DC-link voltage. A capacitor is placed etween these two converters which is used to decrease the voltage ripple.

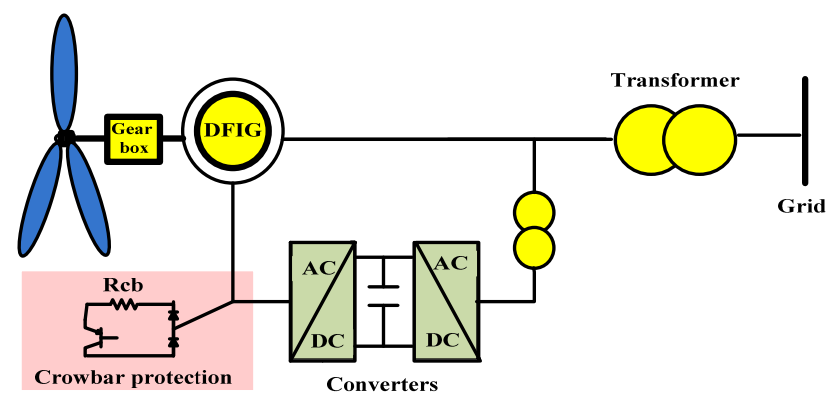

Fig. 1. Doubly fed induction generator

A vector controlled DFIG based on [16], is used to investigate the impacts of SMES on the DFIG performance during fault and voltage swell events. Current reference PWM (CRPWM) and sinusoidal PWM (SPWM) methods are used to control the RSC and GSC, respectively. As noted, the DFIG rotor current is increased by occurring voltage dip at the DFIG terminal which may damage the DFIG converters. The general approach to solve this problem is making a short circuit in the rotor windings with the crowbar protection. In this paper, crowbar control strategy that is proposed in [17], is applied to protect DFIG converters. In this method, the hysteresis comparator is used to compare the rotor current with the preset values of $\mathrm{I}_{\mathrm{L}}$ and $\mathrm{I}_{\mathrm{H}}$. As the rotor current becomes more than $\mathrm{I}_{\mathrm{H}}$, the crowbar is activated and when the rotor current becomes less than $I_{L}$ the crowbar is deactivated. The values of $I_{L}$ and $I_{H}$ have been set to $1.9 \mathrm{pu}$ and $2 \mathrm{pu}$, respectively.

\section{B. SMES Modeling}

SMES is a dc current device capable of storing energy in the magnetic field which is generate by dc current flowing through it. The active and reactive power can be absorbed by (charging mode) or released from (discharging mode) the SMES according to system situations. SMES has some advantages compared to other types of storage devices, such as long lifetime, high response speed, high efficiency, etc. Also, the main advantage of the SMES is that it can release large amounts of power for a small period of time. Also, the number of charging and discharging operations are unlimited. Therefore, SMES is applicable for wind generation application. Different types of SMES technologies and their control strategies have been proposed [18]. In this study, a SMES unit with a PWM voltage source converter and DC-DC chopper is applied to investigate its effects on the DFIG LVRT and HVRT capability. The SMES consists of a transformer, a 6-pulse PWM voltage source converter (VSC), a two quadrant DC-DC chopper, a DC link capacitor, and an inductance as a superconducting coil as shown in Figure 2. The Stored energy in the SMES can be calculated as follow:

$$
E_{S M E S}=\frac{1}{2} L I^{2}
$$

Where $E_{\text {SMES }}$ is stored energy, $L$ is the inductance of the SMES and I is the SMES current. The capacity of the SMES is depends on charging and discharging duration and the application of the SMES. In this paper SMES with 0.95MJ capacity is used to evaluate its impacts on the LVRT and HVRT capability of the DFIG.

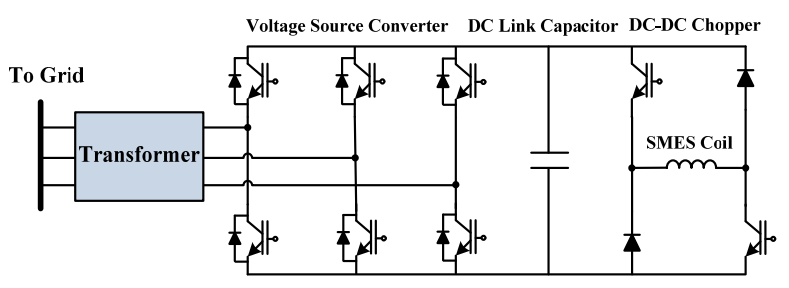

Fig. 2. The SMES topology

The control of the VSC-based SMES is based on [19]. The proportional integral (PI) controllers define the d-and $\mathrm{q}$-axis reference currents by means of the difference between the dc link voltage and reference voltage, and the difference between terminal voltage and reference voltage, respectively. By converting $\mathrm{d}$ - and q-axis voltages which are produced by the difference between reference $\mathrm{d}-\mathrm{q}$ axes currents and their detected values, the reference signal for VSC is created. By comparing the reference signal which is converted to threephase sinusoidal wave with the triangular carrier signal, the PWM signal is produced for IGBT switching. The control system is shown in Figure 3. The dc-dc chopper is used to charge or discharge the superconducting coil. The dc-dc 
chopper is controlled to supply positive or negative voltage to superconducting coil in order to charge or discharge the stored energy. Therefore, the superconducting coil is charged or discharged by regulating the average voltage across the coil which is determined by the duty cycle of the DC-DC chopper. Then the reference signal is compared with the triangular signal to generate the PWM gate signals for the IGBT of the chopper.

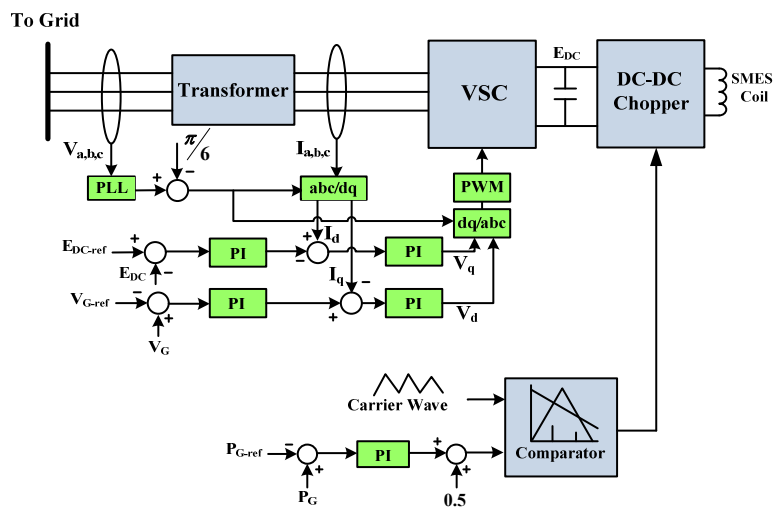

Fig. 3. The control system of the VSC and DC-DC chopper

\section{PROBLEM STATEMENT}

LVRT and HVRT requirements for WTs define the disconnecting instruction of WT from the network. During the occurrence of a fault, the WTs are required to remain connected for a specific amount of time before being allowed to disconnect. A curve rule for LVRT under the U.K. grid code can be found in [20]. According to it, for example, the WT should stay connected to the grid after the terminal voltage reaches $0 \%$ of nominal voltage within $0.14 \mathrm{~s}$ and also it should stay connected to the grid after the terminal voltage reaches $80 \%$ of nominal voltage within $2.5 \mathrm{~s}$. In recent years, different countries such as Spain, Australia, Denmark and USA have forced demanding voltage-time profiles for voltage swell situations. Voltage swells could be initiated by unbalanced faults, large loads switching off and large capacitor banks energizing which may have different durations and magnitudes. This requirement is usually referred to as high voltage ridethrough (HVRT) capability. The HVRT capability curve for Australia can be found in [21]. According to it, the allowed voltage is $1.3 \mathrm{pu}$ for a duration of $0.06 \mathrm{~s}$ [21].

As noted earlier, WTs must stay connected to the power system in case of voltage dip and voltage swell, in compliance with LVRT and HVRT capability. However, DFIG-based WTs are very sensitive to grid voltage variations. Therefore, the DFIG rotor overcurrent caused by voltage dip may damage the rotor side converter and DC link capacitor if no protection scheme is taken into consideration. Also, DFIG rotor surge current caused by voltage swell may damage the DFIG converters. Therefore, to protect the DFIG from the grid voltage dip and voltage swell events, low voltage ride through (LVRT) and high voltage ride through (HVRT) schemes are fundamentally required.

\section{SimULATION RESULTS}

The islanded microgrid shown in Figure 4, is simulated in PSCAD/EMTDC to validate the effectiveness of installing the SMES on the DFIG LVRT and HVRT capability. The test system under study is based on [1] and consists of a $1 \mathrm{MW}$ DFIG wind turbine, one PV system and one synchronous generator. The voltage of the microgrid is $25 \mathrm{kV}$ and the details of the system are stated in Table I.

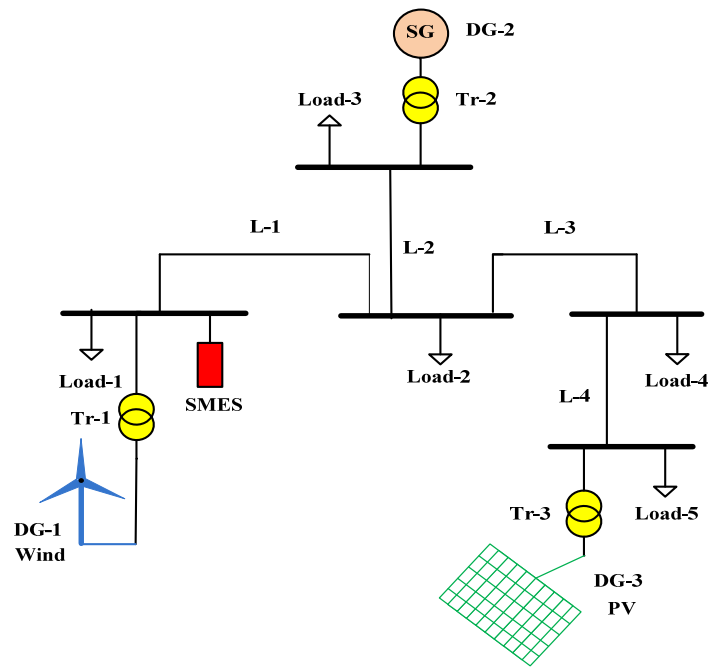

Fig. 4. Microgrid model

TABLE I. MICROGRID PARAMETERS

\begin{tabular}{|c|c|}
\hline Parameter & Value \\
\hline Tr-1 & $0.69-25 \mathrm{kV}, 2 \mathrm{MVA}$ \\
\hline Tr-2 & $5.75-25 \mathrm{kV}, 7 \mathrm{MVA}$ \\
\hline Tr-3 & $0.23-25 \mathrm{kV}, 2 \mathrm{MVA}$ \\
\hline Frequency & $60 \mathrm{~Hz}$ \\
\hline DG-1 & $1 \mathrm{MW}$ \\
\hline DG-2 & $5 \mathrm{MW}$ \\
\hline DG-3 & $1 \mathrm{MW}$ \\
\hline Load-1 & $2 \mathrm{MW}$ \\
\hline Load 3,5 & $1.5 \mathrm{MW}$ \\
\hline Load 4,2 & $1 \mathrm{MW}$ \\
\hline Lines $(20 \mathrm{~km}$ each $)$ & $\mathrm{R}=0.413 \Omega / \mathrm{km}, \mathrm{L}=3.32 \mathrm{e}-3 \mathrm{H} / \mathrm{km}$ \\
\hline
\end{tabular}

\section{A. Fault Event}

In this section, simulation studies are carried out to evaluate the effectiveness of applying SMES to enhance the DFIG LVRT capability in an islanded microgrid. A three-phase fault is applied at $\mathrm{t}=10 \mathrm{~s}$ for a duration of $0.2 \mathrm{~s}$ at the DFIG terminal. The DFIG responses without the SMES are compared with the case with the SMES as shown in Figure 5 and Figure 6. Figure 5 , shows the DFIG rotor current and crowbar operation with and without SMES. It is obvious that, without SMES, the DFIG rotor current increases during fault condition as shown in Figure 5(a). As noted, by increasing the DFIG rotor current, the crowbar protection is activated. The number of crowbar operation in this case is about 47 times (Figure 5(b)). Figure 5(c) and Figure 5(d), show the DFIG rotor current and crowbar operation with SMES. It is clear that by applying the SMES, the rotor current and crowbar operation is decreased. In this 
case, the number of crowbar operations is about 34 times which lead to increase the DFIG controllability during fault condition.
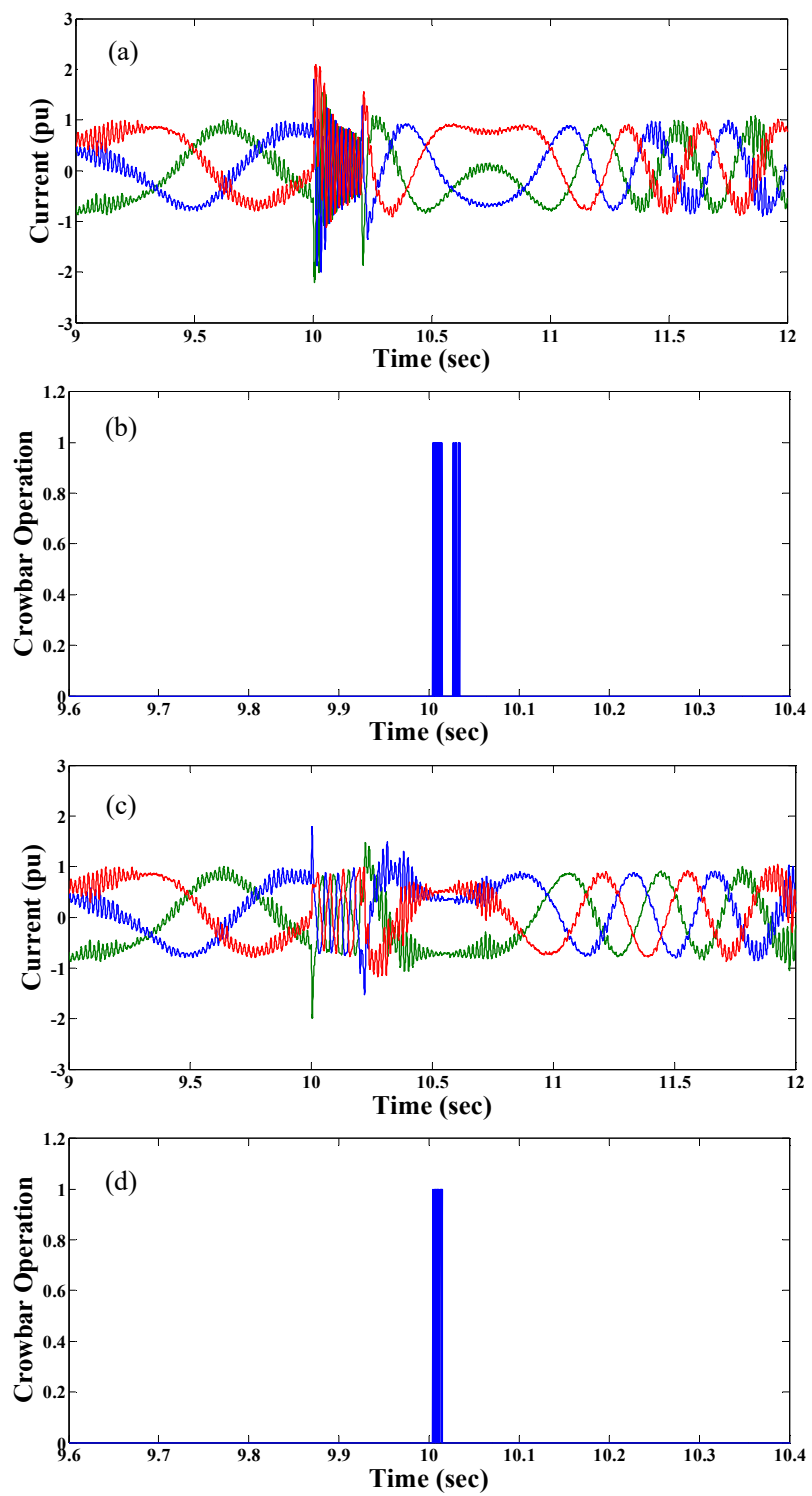

(d)

Fig. 5. DFIG responses to three-phase fault: a) Rotor Current without SMES, b) Crowbar operation without SMES, c) Rotor current with SMES, d) Crowbar operation with SMES.

Figure 6(a), shows the DFIG active power with and without the SMES. The active power of DFIG is decreased to zero during fault condition without the SMES which causes to accelerate the rotor and increase the rotor speed accordingly. By applying the SMES, it injects active power to the microgrid. So the DFIG active power is increased to about 0.2 pu during fault condition. The absorbed reactive power of the DFIG is about $0.22 \mathrm{pu}$ at the fault clearance instant without the SMES as shown in Figure 6(b). By applying the SMES, it injects reactive power to the microgrid during fault condition. Therefore, the DFIG absorbed reactive power is decreased to $0.13 \mathrm{pu}$ which reduces the DFIG terminal voltage drop and enhances the DFIG LVRT capability. The DFIG terminal voltage is shown in Figure 6(c). It is clear that, the terminal voltage is reduced to zero during the three-phase fault without the SMES. After connecting the SMES, the voltage will drop to only $0.3 \mathrm{pu}$ because the SMES injects reactive power to the microgrid during fault condition. The simulation results show that by applying the SMES, the crowbar operation of the DFIG and the absorbed reactive power are decreased during fault condition.
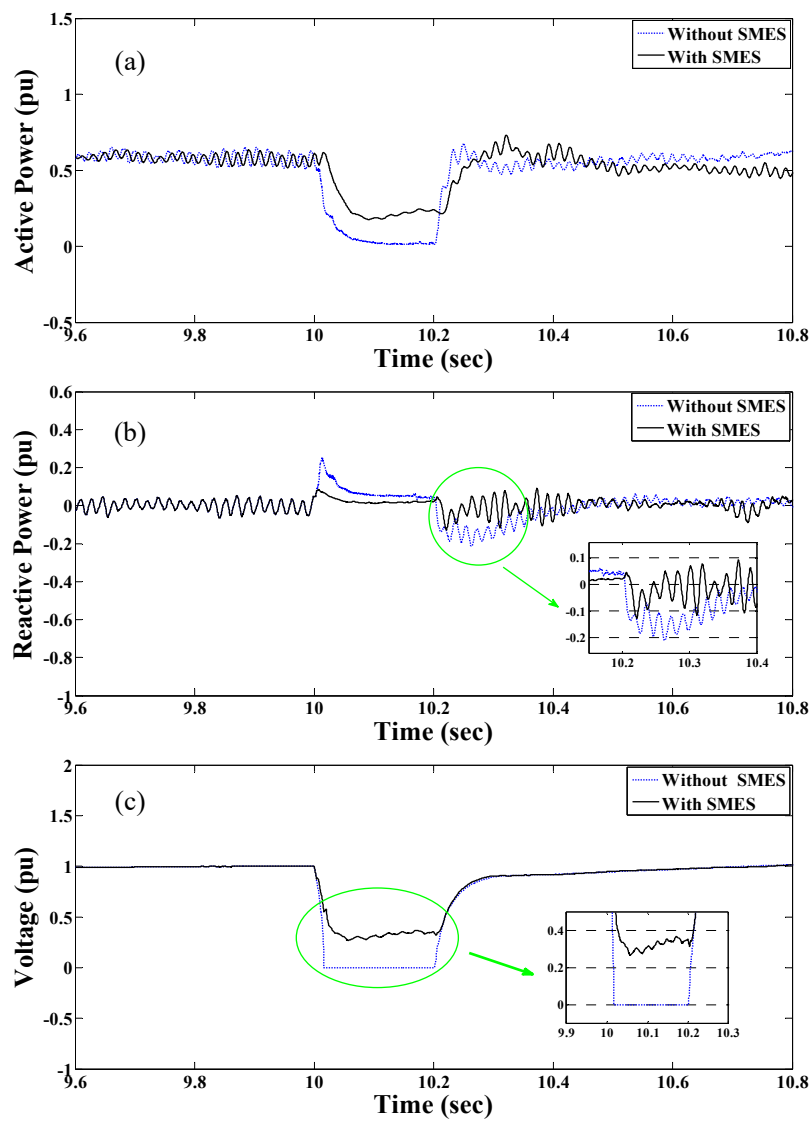

Fig. 6. DFIG responses to three-phase fault with and without the SMES: a) Active power, b) Reactive power, c) Terminal voltage.

So, the performance of the DFIG is enhanced and the LVRT capability of the DFIG is improved during fault condition in the islanded microgrid. Therefore, effectiveness of the proposed approach is validated. Figure 7, shows the transient responses of the SMES during three-phase fault. Before fault occurrence, the SMES current is held constant at its rated value and the SMES is in the standby mode and the maximum energy $(0.95 \mathrm{MJ})$ is stored within the SMES. As fault occurrence at $\mathrm{t}=10 \mathrm{~s}$, discharging mode will take place and the SMES current is decreased. In this condition the stored energy in the SMES is being supplied to the microgrid. After fault clearance at $\mathrm{t}=10.2 \mathrm{~s}$, charging mode will take place and the SMES current is increased. The energy is transferred from the microgrid to the SMES until the maximum capacity of the SMES is reached. So, the SMES has a significant role to improve DFIG LVRT capability during fault condition 

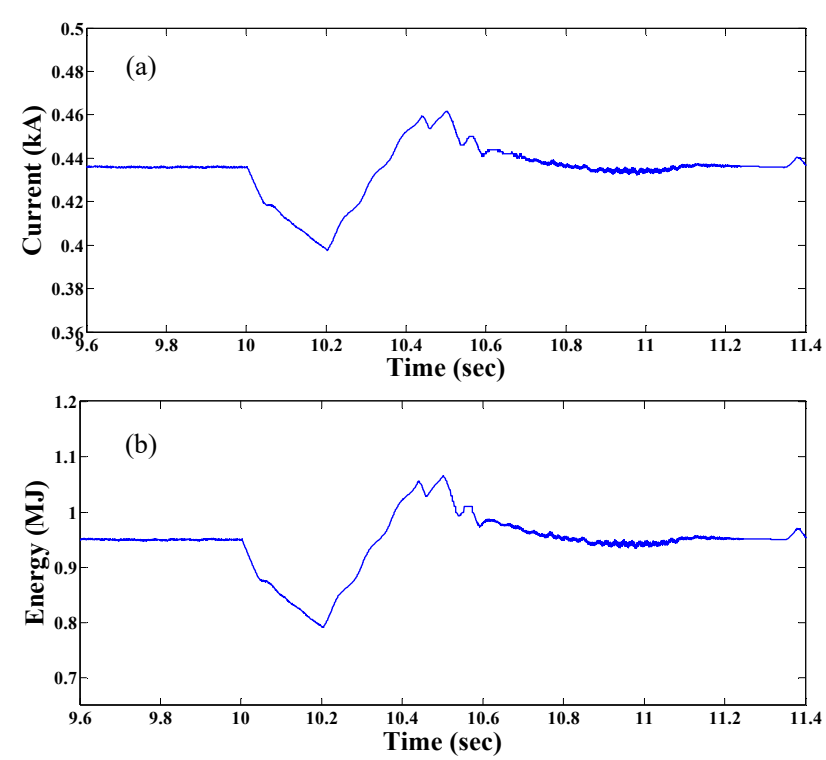

Fig. 7. SMES responses to three-phase fault: a) Current, b) Stored energy.

\section{B. Voltage Swell Event}

In this section a voltage swell is applied to investigate the effectiveness of installing SMES on the DFIG HVRT capability. The voltage swell is applied by increasing the microgrid voltage to $1.25 \mathrm{pu}$ at $\mathrm{t}=10 \mathrm{~s}$ and lasts for $0.05 \mathrm{~s}$. The DFIG responses to voltage swell event with and without the SMES are shown in Figure 8. Figures 8(a) and 8(b), show the DFIG terminal voltage without and with SMES, respectively. By applying the SMES, it absorbs surplus energy from the microgrid during voltage swell events. So, the DFIG terminal voltage is decreased from $1.25 \mathrm{pu}$ to $1.17 \mathrm{pu}$. The active power of the DFIG is decreased to zero during voltage swell without the SMES as depicted in Figure 8(c). By applying the SMES, fluctuation of DFIG active power is decreased. Therefore, the DFIG active power is increased from zero to $0.1 \mathrm{pu}$ with the SMES. So, the stability of the DFIG is improved during voltage swell event by installing the SMES. Figure 8(d), shows the DFIG reactive power with and without the SMES. The DFIG will absorb reactive power about $0.28 \mathrm{pu}$ without the SMES. By installing the SMES unit, the amount of absorbed reactive power is decreased from $0.28 \mathrm{pu}$ to $0.18 \mathrm{pu}$. So, the voltage stability of the DFIG is enhanced during voltage swell event by applying the SMES. Therefore, simulation results confirm that by applying the SMES, the DFIG HVRT capability is improved during voltage swell events. The transient responses of the SMES during voltage swell event are shown in Figure 11. Before voltage swell occurrence, the SMES is in the standby and the maximum energy $(0.95 \mathrm{MJ})$ is stored within the SMES. As the voltage swell occur, the SMES current is increased and charging mode will happen.

In this condition the energy is transferred from the microgrid to the SMES until the maximum capacity of the SMES is reached (1.05 MJ to allow for power modulation during voltage swell event). As the voltage swell clears at $\mathrm{t}=10.05 \mathrm{~s}$, discharging mode will take place and the SMES current is decreased. So, the stored energy within the SMES is transferred to the microgrid until the SMES nominal energy capacity $(0.95 \mathrm{MJ})$ is reached. Therefore, the SMES absorbs surplus energy from the microgrid and the DFIG HVRT capability is enhanced.
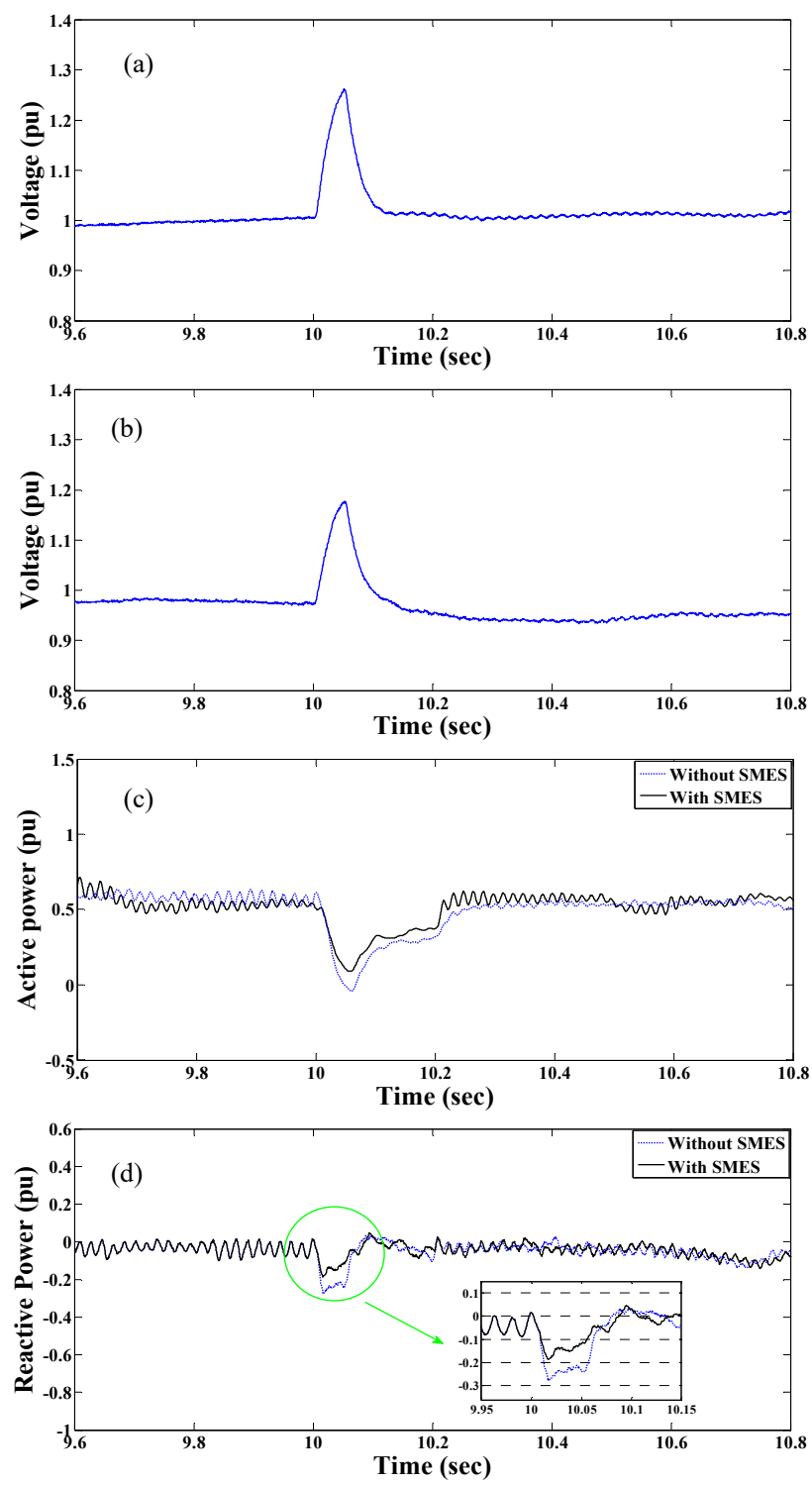

Fig. 8. DFIG responses to voltage swell event with and without SMES: a) Terminal voltage without SMES, b) Terminal voltage with SMES, c) Active power, d) Reactive power.

\section{CONCLUSION}

In this paper, a new application of the SMES is proposed to enhance the LVRT and HVRT capabilities of a DFIG-based wind turbine in the islanded microgrid. The simulation results illustrate that DFIG transient responses are improved and the DFIG LVRT and HVRT capabilities are enhanced during faults and voltage swells. Due to the recent development of high temperature superconductors, the proposed scheme is simple and easy to implement. Also, the proposed approach has high response speed and high rotor current limitation capability. 

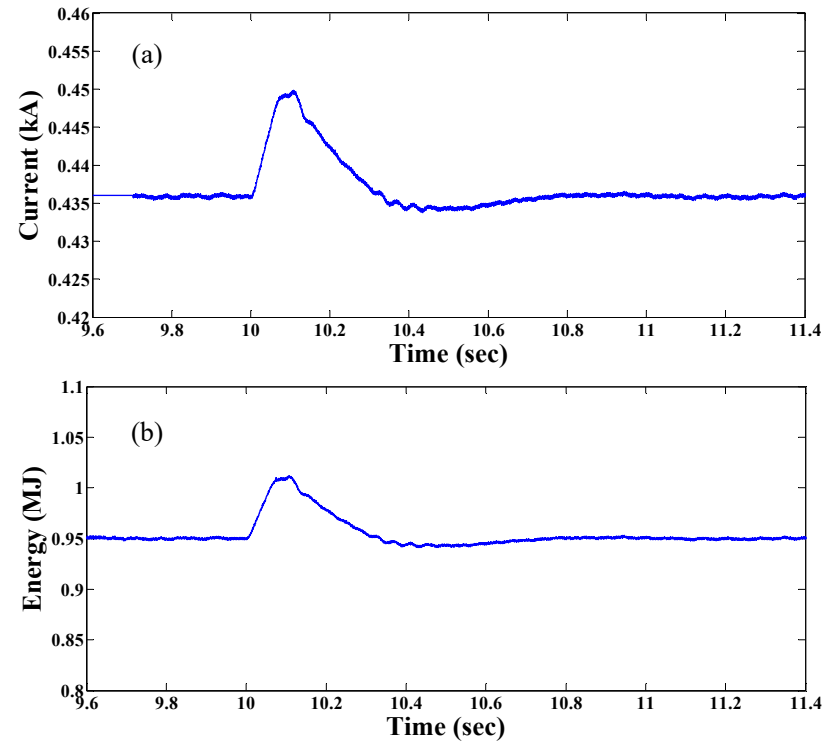

Fig. 9. SMES responses to voltage swell event: a) Current, b) Stored energy.

\section{REFERENCES}

[1] Y. Xu, W. Zhang, G. Hug, S. Kar, Z. Li, "Cooperative Control of Distributed Energy Storage Systems in a Microgrid", IEEE Transactions on Smart Grid, Vol. 6, pp. 238-248, 2015

[2] Global Wind Energy Council, Global Wind Report 2016 - Annual market update, available at: http://gwec.net/publications/global-windreport-2/global-wind-report-2016

[3] S. Yang, T. Zhou, L. Chang, Z. Xie, X. Zhang, "Analytical Method for DFIG Transients During Voltage Dips", IEEE Transactions on Power Electronics, Vol. 32, pp. 6863-6881, 2017

[4] Z. Xing, Q. Tingyu, X. Zhen, C. Renxian, "Dynamic analysis of doubly fed induction generator during symmetrical Voltage swells", Second International Conference on Mechanic Automation and Control Engineering (MACE), pp. 1245-1248, 2011

[5] C. Feltes, S. Engelhardt, J. Kretschmann, J. Fortmann, F. Koch, I. Erlich, "High Voltage ride-through of DFIG-based wind turbines", 2008 IEEE Power and Energy Society General Meeting - Conversion and Delivery of Electrical Energy in the 21st Century, pp. 1-8, 2008

[6] A. F. Abdou, A. Abu-Siada, H. R. Pota, "Improving the low Voltage ride through of doubly fed induction generator during intermittent Voltage source converter faults", Journal of Renewable and Sustainable Energy, Vol. 5, No. 4, pp. 043110, 2013

[7] L. Chen, C. Deng, F. Zheng, S. Li, Y. Liu, Y. Liao, "Fault Ride-Through Capability Enhancement of DFIG-Based Wind Turbine With a FluxCoupling-Type SFCL Employed at Different Locations", IEEE Transactions on Applied Superconductivity, Vol. 25, No. 3, pp. 1-5, 2015
[8] W. Guo, L. Xiao, S. Dai, X. Xu, Y. Li, Y. Wang, "Evaluation of the Performance of BTFCLs for Enhancing LVRT Capability of DFIG", IEEE Transactions on Power Electronics, Vol. 30, No. 7, pp. 3623-3637, 2015

[9] A. O. Ibrahim, T. H. Nguyen, D. C. Lee, S. C. Kim, "A Fault RideThrough Technique of DFIG Wind Turbine Systems Using Dynamic Voltage Restorers", IEEE Transactions on Energy Conversion, Vol. 26, No. 3, pp. 871-882, 2011

[10] M. Molinas, J. A. Suul, T. Undeland, "Low Voltage Ride Through of Wind Farms With Cage Generators: STATCOM Versus SVC", IEEE Transactions on Power Electronics, Vol. 23, No. 3, pp. 1104-1117, 2008

[11] T. Kinjo, T. Senjyu, N. Urasaki, H. Fujita, "Terminal-Voltage and output-power regulation of wind-turbine generator by series and parallel compensation using SMES", IEE Proceedings - Generation, Transmission and Distribution, Vol. 153, No. 3, pp. 276-282, 2006

[12] I. Ngamroo, S. Vachirasricirikul, "Coordinated Control of Optimized SFCL and SMES for Improvement of Power System Transient Stability", IEEE Transactions on Applied Superconductivity, Vol. 22, No. 3, pp. 5600805-5600805, 2012

[13] Q. Huang, X. Zou, D. Zhu, Y. Kang, "Scaled Current Tracking Control for Doubly Fed Induction Generator to Ride-Through Serious Grid Faults", IEEE Transactions on Power Electronics, Vol. 31, No. 3, pp. 2150-2165, 2016

[14] R. Zhu, Z. Chen, X. Wu, F. Deng, "Virtual Damping Flux-Based LVRT Control for DFIG-Based Wind Turbine", IEEE Transactions on Energy Conversion, Vol. 30, No. 2, pp. 714-725, 2015

[15] N. H. Saad, A. A. Sattar, A. E.-A. M. Mansour, "Low Voltage ride through of doubly-fed induction generator connected to the grid using sliding mode control strategy", Renewable Energy, Vol. 80, pp. 583594, 2015

[16] H. Geng, C. Liu, G. Yang, "LVRT Capability of DFIG-Based WECS Under Asymmetrical Grid Fault Condition", IEEE Transactions on Industrial Electronics, Vol. 60, No. 6, pp. 2495-2509, 2013

[17] Y. Ren, W.Zhang, "A novel control strategy of an active crowbar for DFIG-based wind turbine during grid faults", IEEE International Conference on Electric Machines \& Drives Conference (IEMDC), pp. 1137-1142, 2011

[18] M. H. Ali, B. Wu, R. A. Dougal, "An Overview of SMES Applications in Power and Energy Systems", IEEE Transactions on Sustainable Energy, Vol. 1, No. 1, pp. 38-47, 2010

[19] T. Asao, R. Takahashi, T. Murata, J. Tamura, M. Kubo, Y. Matsamura, A. Kuwayama, T. Matsumoto, "Evaluation method of power rating and energy capacity of Superconducting Magnetic Energy Storage system for output smoothing control of wind farm", 18th International Conference on Electrical Machines, Vilamoura, pp. 1-6, 2008

[20] H. M. El-Helw, S. B. Tennakoon, "Evaluation of the suitability of a fixed speed wind turbine for large scale wind farms considering the new UK grid code", Renewable Energy, Vol. 33, No. 1, pp. 1-12, 2008

[21] M. Mohseni, S. M. Islam, "Review of international grid codes for wind power integration: Diversity, technology and a case for global standard", Renewable and Sustainable Energy Reviews, Vol. 16, No. 6, pp. 38763890,2012 